\title{
Quando a festa é rito: uma apreensão dos sentidos em uma roda de samba no Rio de Janeiro
}

\author{
BARBARA GRILLO iD \\ Universidade Federal do Rio de Janeirol Rio de Janeiro, RJ, Brasil \\ barbararsgrillo94@gmail.com
}

DOI 10.11606/issn.2316-9133.v30i2pe181340

\begin{abstract}
resumo Recentemente, uma vasta literatura tem se empenhado em delinear festas populares, como as rodas de samba, por meio de seus aspectos performáticos e rituais. Tomando esses aspectos como elementos chave, os resultados aqui apresentados são derivados de uma pesquisa de cunho etnográfico realizada desde na cidade do Rio de Janeiro. Nesse artigo, busco esmiuçar esses aspectos já caros aos estudos socioantropológicos recorrendo aos sentidos como ferramenta analítica, operacionalizando-as a fim de formular uma análise ritual de rodas de samba organizadas por grupos inteiramente femininos. Nesse sentido, partiremos de uma compreensão da significação simbólica do tempo e do espaço por meio de uma aproximação de sentidos, como a visão, o olfato e a audição.
\end{abstract}

palavras-chaves performance, empoderamento, sentidos, corporalidade, etnografia
When the party is a ritual: an apprehension of the senses in a roda de samba in Rio de Janeiro

abstract Recently, a great amount of literature explored popular culture festivities, as rodas de samba, by its performative and ritualistic aspects. Taking those aspects as key the results presented in the article are based in the ethnographic research conducted since 2017 at Rio de Janeiro. The article seeks to explore well-known socio-anthropological approaches to the subject while using the researcher's senses as the main analytical background. To do so, it comprehends the importance of time and space to the process of symbolic signification in such rituals while exploring the relevance of senses, such as visioning, smelling and hearing.

keywords performance, empowerment, sense, corporality, ethnography

\section{Introdução}

O samba carioca tem sido objeto de inúmeras discussões socioantropológicas, preocupadas em compreender desde sua formação (Vianna, 1994; Sodré, 1998; Sandroni, 2012) até suas formas de sociabilidade, moralidades e valores (Moura, 2004; Lopes, 2008; Trotta, 2011). Entretanto, poucos são os estudos interessados em compreender essas dimensões por meio de uma perspectiva de gênero. Relevantes exceções são os trabalhos de pesquisadoras de diferentes regiões do país cujas pesquisas remontam àquelas dimensões ao levarem em consideração as presenças e o protagonismo das mulheres no samba (Couto, 2009; Santanna, 
2019). Nesse sentido, é a essa lacuna que o presente trabalho se esforça em trazer alguma contribuição.

O texto a seguir baseia-se em uma pesquisa etnográfica realizada entre os anos de 2017 e 2018 na cidade do Rio de Janeiro. Naquela pesquisa, o principal objetivo foi acompanhar dois grupos de samba inteiramente femininos, figurantes do cenário musical da juventude das zonas sul e central da cidade: o Samba que Elas Querem (doravante, SQEQ) e o Moça Prosa (MoP). Àquela altura, ambos os grupos se apresentavam costumeiramente em ambientes abertos, naquilo que chamavam "rodas de rua". De enorme valor para as musicistas dos dois grupos, esses eventos costumavam acontecer no eixo ligando os bairros da Glória, da Lapa e do Centro. Com o passar do tempo, a possibilidade de realizarem esses eventos "de rua" se tornou cada vez mais rara, devido a dificuldades burocráticas e organizacionais (pois, quanto maior o público presente, mais difícil torna-se realizar um evento de rua). Mesmo assim, as reflexões propostas a seguir baseiam-se na experiência etnográfica em meio a essas rodas de rua.

Centralmente, a pesquisa buscava compreender os acontecimentos daqueles eventos, elaborados por aqueles grupos de mulheres, jovens e integrantes do circuito de jovens sambistas cariocas, de uma geração novíssima. Além disso, eram preenchidos de sentido adicional a partir da apreensão de narrativas e proposições feministas contemporâneas. Em pouco tempo, aquelas rodas se tornaram "point de encontro" de uma juventude de classe média alegadamente preocupada com questões de gênero. Assim, um dos principais temas de mobilização dentre as musicistas e seus públicos era o "empoderamento das mulheres no samba".

Em dezembro de 2017, em uma roda no bairro da Glória, no Bar dos Irmãos, a vocalista de um dos grupos manifestou-se em relação a uma espécie de acusação feita por um outro sambista. Segundo ele, aquelas mulheres só faziam sucesso pois eram "bonitinhas", que, na verdade, não teriam "samba no pé” - esse um "pré-requisito" para levar à cabo rodas de samba de acordo com muitos dos meus informantes. Ao colocarem-se, em meio à roda, firmemente contra a deslegitimação daquele músico, as sambistas diziam que, apesar do inconveniente, iriam responder aquele homem "pela música", ou seja, responderiam por suas performances corporais. Dessa forma, tal situação parece interessante pois demonstra que a mobilização daquelas sambistas causava, a priori, a desestabilização de dois elementos chave para a experiência de vida das interlocutoras. Por um lado, o que se entendia por "mulheres da roda de samba" passava por confrontamento, enquanto, por outro, a própria concepção de "roda de samba” era tensionada por meio das performances.

Nesse sentido, nas próximas páginas demonstrarei os processos de tensionamento desses elementos. Assim, a compreensão do movimento de empoderamento daqueles musicistas é central para que possamos nos aproximar da categorização de "mulheres da roda de samba" levada a cabo por elas. Ainda, uma aproximação do tensionamento em relação à categoria "roda de samba" levará em conta a disposição de valores temporais e espaciais associados aquelas rodas, 
que criam significação e sentido às experiências rituais a partir da mobilização dos sentidos, como a visão, o olfato e a audição.

\section{As rodas de samba dos grupos femininos}

Os grupos SQEQ e MoP realizavam rodas de samba tanto em espaços abertos, na rua, quanto em casas de show espalhadas pela cidade, principalmente aquelas do Centro e alguns bairros da zona sul da cidade. O MoP era um grupo mais antigo, surgido ainda em 2012, durante uma oficina de instrumentos percussivos direcionada ao público feminino, o Bambas de Saia, na Pedra do Sal - espaço da zona portuária reconhecido como um espaço importante para o samba carioca. Já o SQEQ era um grupo surgido ainda no ano de 2017, durante a reunião de algumas musicistas diante do aniversário de uma de suas vocalistas, no bairro da Glória, na zona sul da cidade. Embora com apresentações públicas muitas vezes diferentes, ambos os grupos apresentavam o empoderamento como parte de suas apresentações mais formais à mídia e/ou nas redes sociais. Nessa altura, cabe ressaltar que a composição racial de ambos os grupos era diversa: ali existiam mulheres negras e brancas, além de outras com categorias raciais diversas. Nesse sentido, mesmo não sendo compostos inteiramente por mulheres negras, a pauta do empoderamento das mulheres encontrava-se muitas vezes com a necessidade de reconhecer o protagonismo das mulheres negras no samba.

As apresentações desses grupos costumavam acontecer no final do dia, começando aproximadamente às 18 horas e indo até o começo da madrugada, a depender da área onde se apresentavam. ${ }^{1}$ Ao chegar aqueles espaços, era comum nos depararmos com um grande toldo, que servia de abrigo à mesa das sambistas, sempre centralizada naqueles espaços. Ao redor dessa mesa organizavam-se os demais elementos das festas, como a mesa de som e amplificação, as mesas de bares, um pouco mais distantes as plataformas dos vendedores ambulantes de bebidas e alimentos. Preenchendo a disposição do espaço estava o público, composto por um número expressivo de mulheres, fato que alterava não apenas a primeira impressão sobre corpos mais intuitivamente associados às rodas de samba, os masculinos, mas também a ideia de coro do público. Nesse, em vez da expectativa de um coro caracterizado por vozes graves e gritantes, chocavam vozes melodiosas e normalmente mais agudas.

Embora surgidos em momentos bastante diferentes, os dois grupos faziam parte de um mesmo circuito de jovens (Magnani, 2005), ou seja, compartilhavam espaços, valores e moralidades dentre um grupo da juventude carioca. Nele, as pautas feministas contemporâneas ganharam força especial quando esses grupos de mulheres passaram a mobilizar a questão do

\footnotetext{
${ }^{1}$ As zonas residenciais do Rio de Janeiro possuem leis de regulação de horário bastante significativas, costumeiramente seguidas à risca pelos bares onde as musicistas se apresentavam, localizados em bairros de classe média: Glória, Catete, Botafogo. Entretanto, quando em bairros mistos, residenciais e comerciais, como o Centro e a Lapa, o horário de fim das apresentações guiava-se por outros critérios.
} 
empoderamento para chamar atenção sobre seus espaços dentro das rodas de samba da cidade. Embora alinhadas à compreensão de que a realização daquelas rodas era algo importante para elas mesmas, nem todas as musicistas consideravam-se feministas à época, como uma das percussionistas do SQEQ me contou certa vez, em maio de 2018. Tal elemento é relevante pois evidencia que, se ali existia qualquer forma de reflexão política quanto ao tema, ela não era compartilhada de forma homogênea e tocava as musicistas engajadas - e, provavelmente, também o público - de maneiras diferentes. Nesse sentido, apesar de unidas para a organização das rodas, as motivações das musicistas costumavam ser diferentes.

Para além disso, é importante pontuar em que momento, e como, passo a me aproximar

desses grupos. À época, comecei minha pesquisa nas rodas do SQEQ e, em seguida, passei a frequentar também as do MoP. Embora não seja uma musicista, sempre estive envolvida com atividades culturais que envolvessem a música popular brasileira e, muitas vezes, o samba sempre como espectadora ou aluna de professoras/es de canto e de instrumentos musicais. Por outro lado, a questão do empoderamento fazia parte do meu repertório crítico também há algum tempo, dado meu interesse em relação à teoria e à prática feministas. Assim, a junção de dois temas mobilizadores de importantes elementos da minha vivência, enquanto uma mulher jovem (branca e de classe média), foi fator central para o início de meus questionamentos, que buscavam criar alguma perspectiva em relação a tópicos que me pareciam, a princípio, próximos. Logo, foi assim que eu, como uma estudante de antropologia, me aproximei daquilo que se transformaria em meu objeto de estudo durante os anos de mestrado: as rodas de samba de grupos inteiramente femininas.

\section{A questão do empoderamento feminino}

Ao longo dos últimos anos, autoras como Sardenberg (2006) apontam que o empoderamento, tanto como pauta política quanto como categoria analítica, pode ser compreendido dentre duas possibilidades: uma que se associa à noção de "desenvolvimento" e outra que se pauta por aquilo convencionalmente lido por "agência”. Ou seja, por um lado, ao tratar o empoderamento a partir de uma lógica do desenvolvimento, especialmente econômico, existe uma crescente literatura crítica relativa à incorporação da temática às práticas pertencentes à agenda neoliberal (Batliwala, 2007; Chakravarti, 2008; Cornwall, 2018). Embora o empoderamento não seja um tema muito comumente tratado por autoras e autores interessados pela temática das mulheres e do samba carioca, é possível notar a conexão entre empoderamento e desenvolvimento econômico no relevante trabalho de Miranda (2019), cujos esforços remontam as trajetórias das mulheres quilombolas de Tijuaçu, que mobilizaram o Samba de Lata como ferramenta de recuperação (e empoderamento) socioeconômico frente à grave crise da seca e da pobreza vivenciada pelo município. Nesse sentido, é central pontuar que 
as dimensões socioeconômicas não estão alheias aos processos entendidos como empoderantes, mesmo que essas dimensões não sejam o objeto de análise do presente trabalho.

Por outro lado, há uma relevante bibliografia preocupada em apontar o empoderamento como parte das tramas envolvendo as relações sociais e a corporalidade (Mizrahi, 2015; Berth, 2018). A corporalidade é um tema amplamente discutido pela literatura socioantropológica feminista (Adelman, 2003; Piscitelli, 2007). Nela, as relações com o corpo tornam-se fonte de análise para diversas interações cujas bases remontam às estruturas diferenciantes e desiguais. Uma recente literatura busca evidenciar o corpo como um importante mediador de valores, moralidades e atitudes, delineando novas apreensões sobre o empoderamento, baseadas, sobretudo, em concepções acerca da estética e dos afetos de atores sociais diversos. Nesse sentido, tanto Mizrahi quanto Berth estabelecem uma importante discussão entre empoderamento e corporalidade, tomando como referência os cabelos negros. Se, para elas, os cabelos são pontos de partida; neste trabalho, um corpo sensível, que serve de instrumento (pela voz) e que mobiliza instrumentos musicais, torna-se protagonista.

Assim, se para Berth (2018), os cabelos são um instrumento de autoafirmação e criação de afeto para populações marcadas por relações discriminatórias, como a negra; para Mizrahi (2015), os cabelos são mediadores entre atores sociais (mulheres negras) e os fluxos de pessoas nas cidades, sendo esses negociados em meio a estruturas desiguais. Isso posto, cabe dizer que uma compreensão a partir da ideia de mediação parece mais adequada aos objetivos deste artigo. Assim, a mediação estabelecida entre a criatividade daquelas mulheres e o cenário musical do samba mostra-se um elemento central para a compreensão de suas presenças no "mundo do samba" por meio do "empoderamento". Nesse sentido, as práticas das sambistas, ou seja, suas performances corporais mediavam uma espécie de reconhecimento de suas presenças naquele cenário musical - entendido, com frequência, como especialmente masculino, segundo elas me contaram.

\section{"Naquele dia, eu me senti empoderada"}

Em 2020, tive uma conversa com uma das musicistas dos grupos que estudei. Naquela tarde, a violonista me contava sobre como se sentia em relação aos esforços que ela e seu grupo faziam para firmarem-se no cenário musical do samba carioca. Ela me narrou uma experiência na qual haviam compartilhado o palco com importantes figuras do "mundo do samba", quando me disse de forma bem-humorada: “Bárbara, naquele dia, eu me senti empoderada!". Ao afirmar isso, a violonista me dizia, mais uma vez, aquilo que ela e outras interlocutoras haviam colocado ao longo da pesquisa: o empoderamento sobre qual falavam dizia respeito ao reconhecimento de uma experiência, sobretudo, corporal. Era a forma e os atravessamentos daquele tocar que informava às interlocutoras um "empoderamento". 
Ao longo da pesquisa, os relatos das musicistas indicavam que a questão não era simplesmente estarem presentes nas rodas, pois isso, em parte, já era verdade. Para aquelas mulheres, a importância daquele movimento era pautar o tipo de presença que desejavam exercer no cenário musical das rodas de samba cariocas. Logo, a partir de lugares consolidados, como os de intérpretes, cantoras e, por vezes, "musas", elas estavam dispostas a requerer outros espaços, anteriormente negados às mulheres, segundo elas me contavam. Dessa maneira, ao empoderarem-se, elas buscavam "entrar pra roda" como instrumentistas, compositoras, arranjadoras e organizadoras daqueles eventos. Essa entrada, nos termos desejados por elas, era ponto de inflexão para uma renegociação da categoria "mulheres da roda de samba".

Esse "entrar pra roda" era legitimado por elas principalmente ao recorrerem a dois elementos: suas trajetórias musicais e experiências corporais. Elas mobilizavam, por exemplo, os vínculos às instituições, aos grupos e às pessoas ao longo de suas trajetórias musicais. Em primeiras conversas, era comum que elas me contassem onde haviam estudado música (a Unirio e/ou a Escola Portátil de Música eram citadas frequentemente), caso fossem estudantes ou universitárias; com quais grandes figuras do cenário do samba já haviam tocado; ou até mesmo de quais outros grupos já haviam feito parte. Entretanto, elas também mobilizavam suas experiências enquanto musicistas, relacionando-se com as técnicas de canto e instrumentais que desenvolveram em meio àquelas trajetórias, valorizando suas técnicas musicais e "corporais" (Mauss, 2017). Por isso, era comum que elas me contassem um interesse por um novo instrumento ou por uma nova forma de participar das rodas, às vezes como compositoras ou arranjadoras. Assim, demonstravam seus corpos como instrumentos, no caso da voz, e mobilizadores de instrumentos musicais, no caso dos violões, cavaquinhos, flautas, pandeiros etc., notabilizando-os por processos de aprendizagem e experiência (Gonçalves, 2008).

Dessa maneira, por um lado, é possível identificar a importância daquilo que Saba Mahmood (2005) chama de "práticas de vida" em meio às narrativas das interlocutoras. Guiadas por normativas e valores associados a uma "forma de tocar referenciada" (Solis, 2017), elas buscavam por meio de instituições formadoras - ainda que fossem figurantes do cenário musical masculino com o qual elas se chocavam - alicerces legitimadores de suas atuações musicais. Assim, elas agiam por meio de referências bem aceitas entre os agrupamentos interessados a fim de reafirmarem a disputa por suas presenças e reconhecimento. Por outro lado, o empoderamento por elas afirmado recorria à evidenciação de suas experiências corporais. Logo, ao valorizarem suas performances corporais, as sambistas acabavam dando sentido àquelas presenças por meio da importância das técnicas corporais ali mobilizadas, frutos de aprendizado e experienciação produzidos ao longo do tempo. Dessa maneira, trajetórias também podem ser entendidas como base analítica para evidenciar o conhecimento corporal adquirido pelas interlocutoras. 
Nesse sentido, ao longo da pesquisa, aquilo chamado pelas musicistas como empoderamento aparecia como um elemento de mediação quanto as suas presenças nas rodas de samba. Essa mediação era capaz de associar dois eixos: o reconhecimento de suas experiências e de suas trajetórias. Ainda, ao se alinharem às concepções e disposições de um "samba de raiz", as musicistas expressavam o desejo de disputar suas presenças ainda fazendo uso de recursos típicos às rodas de samba, ditas tradicionais, da cidade. Para isso, tanto os espaços de suas apresentações quanto a temporalidade desses acontecimentos eram centrais para a eficácia da significação daquele movimento. Por isso, na próxima seção, busco trazer algumas reflexões acerca dessas premissas.

\section{O tempo e o espaço de uma roda}

Em “Os sentidos no espetáculo" (2002), Maria Laura Cavalcanti demonstra a importância da apreensão simbólica do espaço e do tempo para a análise dos rituais. Além disso, a autora mostra a importância dos sentidos, especialmente da visão e da audição, para uma aproximação analítica dos espetáculos pesquisados: o Carnaval Carioca e a Festa do Boi de Parintins. Dessa maneira, a autora não só nos alerta para a relevância da análise do espaço e do tempo, como indica um caminho para a operacionalização do uso dos sentidos em pesquisas socioantropológicas.

No que se refere às rodas de samba, o espaço e o tempo também são marcadores essenciais à compreensão dessas festas. Trabalhos recentes, como os de Cristiano (2016) e Moura (2004), são capazes de oferecer importantes insights a respeito da disposição temporal e espacial das rodas de samba cariocas. Enquanto Moura (2004) chama atenção para a roda como um momento de fuga (pelo tempo) do sambista em relação ao alargamento da perspectiva mercadológica no carnaval do Rio de Janeiro, Cristiano (2016) descreve a organização espacial da roda por meio da disposição dos corpos de sambistas e público naquilo que chama de "anéis". Em “No princípio, era a roda”, Moura (2004) constrói uma espécie de gênese das rodas de samba cariocas. Segundo o autor, embora o festejo em roda não seja exclusivo às rodas de samba, esse formato de encontro entre sambistas tornou-se popular já no século XX diante da mercantilização do carnaval carioca. O sentimento de perda das escolas e grêmios carnavalescos, leva os sambistas da época a buscarem um refúgio para o samba, e para si mesmos, por meio das rodas. Assim, o tempo desgovernado e flexibilizado do festejo ajudava a garantir e prometer o sentimento de refúgio almejado pelos sambistas de então. Como os sambistas de meados do século passado, aquelas sambistas valorizavam a flexibilização do tempo das rodas. A permanência até o final do festejo não indicava apenas o gosto pela musicalidade dos grupos, mas também a identificação em relação à temporalidade sambista: como "inimigos e inimigas do fim”. 
Já ao refletirmos sobre o espaço, Cristiano (2016) demonstra a importância da disposição do público em anéis durante rodas de samba na zona oeste carioca. Para o autor, era essa organização de espaço que possibilitava a interação entre os sambistas e quem os escutava, criando relações de identificação entre público e sambistas. Um tipo de relação evidenciada pelo autor diz respeito à identificação mútua entre sambistas e público, criando um senso de pertencimento entre os dois grupos. Para evidenciar essa relação, o autor cria a categorização de "público cativo". Esse público era composto não só por pessoas mais próximas aos músicos, mas também por pessoas que se interessavam em permanecerem próximos à mesa dos sambistas. Assim, a mesa de alguma maneira servia não só para organizar o espaço, mas também para atribuir senso de pertencimento. A mesa se mostrou um elemento de forte significação para as interlocutoras de minha pesquisa. Era comum encontrar apresentações, mesmo em casas fechadas, onde a princípio não seria necessário o uso de uma mesa, com uma disposição de palco que viabilizasse a presença da mesa das sambistas.

A flexibilização do tempo, bem como a organização dos espaços, tendo a mesa como significante central e de centralização, são facetas do tempo e do espaço cuja apreensão mostrouse relevante para criar um olhar mais próximo e atento ao que seriam aquelas rodas de samba performadas pelas interlocutoras. O entendimento sobre a significação criada por esses elementos à roda de samba, aqui compreendida como ritual, demonstra a importância de um olhar para o tempo e para o espaço quando buscamos nos aproximar da dramaticidade e significação (Turner, 1974) empenhadas por cada rito.

\section{Para uma compreensão dos sentidos}

"O corpo é o filtro pelo qual o homem se apropria da substância do mundo e a faz sua por intermédio dos sistemas simbólicos que partilha com os membros de sua comunidade." (Le Breton, 2016:13)

Embora os estudos sobre os sentidos não sejam uma novidade, evidenciando-se ao menos desde os escritos de filósofos pré-socráticos, como Aristóteles e Platão, a partir da década de 1990, a antropologia, a sociologia e a própria filosofia abrem-se à discussão sistematizada do tema. Tal discussão parte de uma denúncia à epistemologia "Ocidental", que tomaria a visualidade como sentido central à criação de significados dentre os modos de vida (Classen, 1993; Urry, 1999; Ingold, 2008). Dessas denúncias, surgem inúmeros trabalhos, preocupados em oferecer ferramentas analíticas e teóricas, atentas à composição dos modos de ser e estar por outros sentidos, especialmente o tato e o odor (Cefaï, 2010; Classen, 2012; Jaquet, 2014). 
A literatura preocupada em compreender os sentidos na elaboração dos modos de ser empenha-se em evidenciá-los como parte elementar da construção de conhecimento e, nesse sentido, investem a corporalidade de técnica (Jaquet, 2010; Le Breton, 2016). Tal corporalidade pode ser compreendida a partir de duas chaves: a da 1) percepção (Le Breton, 2016) e a da 2) imaginação (Jaquet, 2010). Assim, se Le Breton inspira-se centralmente nos postulados fenomenológicos de Merleau-Ponty (2018), Jaquet retoma as formulações espinozianas sobre o sentir. Embora embasados em raízes filosóficas distintas, tanto Le Breton quanto Jaquet evidenciam os sentidos como elementos chave, e iniciáticos, dos processos de significação e de criação de significados, ou seja, à elaboração de sistemas simbólicos.

Apesar de tal proposição assumir alguma homogeneidade dentre os pesquisadores e pesquisadoras interessadas no tema, ainda há um relevante debate analisado por Ingold (2008) e Le Breton (2016). Nele, os autores interessam-se por definir o que pode ser considerado como o começo e o fim dos sentidos, entretanto, enquanto Le Breton reflete a transformação do sensível em inteligível, entendendo que "sentir o mundo é outra maneira de pensá-lo" (2016: 29); Ingold discute a importância do sensível para a produção de sentido (das ações). De qualquer maneira, ambos compartilham parte central do diagnóstico: a questão só pode ser respondida a partir de uma reavaliação das relações entre a mente, o corpo e o ambiente. Nesse sentido, ao formular sua "metafísica alternativa da visão", Ingold (2008) afirma: "o processo da visão consiste em um processo interminável, um engajamento de mão dupla entre o perceptor e seu ambiente.” (Ibidem: 17).

Esse engajamento constitui um corpo que não é simplesmente interventor, mas também atravessado pelo ambiente, primariamente, pelos sentidos. Essa forma de envolvimento é central para aquilo apresentado por Le Breton (2016) como conhecimento (Ibidem: 32) e por Jaquet (2010) como transformação (Ibidem: 22). De alguma maneira, essas formas de se relacionar com o mundo podem ser entendidas a partir do reconhecimento do acúmulo de aprendizado e da abertura às experiências corporais e sensíveis. Nesse sentido, essa dimensão pode informar sobre uma integração aos sistemas simbólicos de cada grupo social, o que neste trabalho tem sido pensado a partir da participação de um grupo de mulheres a um modelo de roda de samba dito "tradicional" ou "de raiz". Ainda, como posto anteriormente, tal dimensão mostrou-se mediada pela noção de "empoderamento", ressignificada por aquelas mulheres sambistas, relacionando-a, sobretudo, ao aprendizado e à experiência. Assim, o empoderamento do qual falavam mostra-se em íntima relação à condição corporal.

Entretanto, naquela experiência etnográfica, tal condição não era exclusiva às artistas, mas profundamente compartilhada entre quem estivesse naquelas rodas de rua. Por isso, nas próximas páginas, trago uma reflexão sobre a experiência etnográfica conduzida, reavaliando-a como uma experiência, também, sensível. 


\section{A festa encontra os sentidos}

$\mathrm{Na}$ introdução à coletânea Ritual e Performance, retomando a tradição antropológica clássica dos estudos dos rituais, Cavalcanti (2014) define rituais como

agregados de conduta e ações simbólicas que, sempre feitos e refeitos no curso do tempo, permeiam a experiência social conferindo-lhes graça, intensidade e ritmos próprios. Sua principal característica, ou seu principal apelo, é o fato de nos trazerem sempre para o solo vital e concreto da experiência humana - feita de cores, sabores, cheiros, visualidades, danças, gestos, vocabulários, pensamentos, melodias, interações e relações, processos, conflitos e tensões, sentimentos, emoções e afeições. (Cavalcanti, 2014: 10)

Assim, o ritual é pensado analiticamente por meio de experiências humanas concretas compreendidas como ações simbólicas.

Entretanto, há outro aspecto de análise ritual preocupado em averiguar aquilo que alguns e algumas pesquisadoras chamam, com algumas diferenças, de "eficácia da ação simbólica" (Cavalcanti, 2014; Peirano, 2006). Analiticamente, essas pesquisadoras utilizam a noção de

performance para enfatizarem a eficácia das ações simbólicas. Nesse sentido, Cavalcanti (2013) define a performance como o "ponto de chegada da experiência social" (.: 423). Assim, a performance pode ser compreendida, dentre inúmeras possibilidades de realização que exigem a corporalidade dos atores sociais, como uma situação comunicativa caracterizada pela simultaneidade de presença entre quem observa, um público, e quem performa, no caso das rodas, os e as musicistas envolvidas. Nessa situação presencial, o símbolo ritual e a experiência social se completam e fazem sentido afetivo, social e político. Assim, a performance ritual, como uma experiência distinta à vida cotidiana dentro da qual se insere, evidencia, como uma mensagem via corpo, a experiência social em curso entre todos e todas que compartilham aquele momento.

Entretanto, um ritual nunca se repete, ele se mantém ao longo do tempo por suas reinvenções. Quando reincidentemente vamos a um evento ritual, seja religioso ou artístico, com o tempo desenvolvemos a ideia de que já conhecemos aquilo. Esse conhecimento não advém de uma repetição ou de permanências. $O$ sentimento de conhecimento parte do entendimento das poéticas em jogo em cada um desses rituais, pois há uma espécie de conhecimento sentimental e sensível ali compartilhado. Quando há uma conexão inexplicável, e que nem sequer requer explicação, entre quem performa esses rituais, nota-se que essas poéticas são compartilhadas por todos e todas. 
De algum modo, essas poéticas se tornam compreensíveis por aquela dimensão humana da experiência, parte integrante e inalienável de um ritual. Em parte, meu trabalho foi compreender quais eram as poéticas vivenciadas e compartilhadas por quem estivesse naquelas rodas de samba. Foi só a partir da conexão com essa dimensão dos acontecimentos que pude entender muito daquilo que minhas interlocutoras, alguns informantes e pessoas ao me redor me apresentavam. A entrega à experiência humana dos rituais que me propus foi um caminho necessário para entender a singularidade das experiências em jogo. Logo, surgiu a alteridade: não só aquelas identitárias relacionadas à raça, ao gênero e à sexualidade, mas também e, talvez principalmente, de experiências.

A compreensão dessas poéticas pelo uso da sensibilidade também parte de um outro pressuposto. Se em grande parte do texto de dissertação de mestrado (Grillo, 2019), me empenhei em descrições sociológicas e antropológicas sobre as formas de consumo, de integração à cidade, de valores e de conexão com a música, acredito que seja importante pontuar que essas descrições só foram possíveis por meio de uma busca também sensível. Esses elementos se tornaram relevantes para minha reflexão posterior pois foram impactantes da minha experiência durante a pesquisa. Mesmo que em meio a um turbilhão de acontecimentos de pesquisa tomassem lugar secundário em minha categorização de "eventos importantes", ao final, a experiência sensível foi uma das personagens mais ativas em meus escritos de campo. Restava ainda operacionalizá-las analiticamente, como aqui me proponho a fazer.

Descrevi todas essas camadas de acontecimentos porque, apenas a partir da compreensão de todas elas, junto às minhas experiências nas rodas, tive acesso à dimensão poética, citada anteriormente. A partir dessa dimensão, tudo aquilo que havia visto ou ouvido integrava-se. Logo, minhas observações sobre empoderamento, percepção do samba na cidade do Rio e o que entendi com minhas interlocutoras faziam sentido principalmente quando pensadas a partir daquela experiência humana, sensível: assim, encontravam espaço fértil para as significações ali em jogo. Além disso, se o ápice dessa forma de experiência acontecia no ritual, ou seja, nas rodas, era também ali que eu compreendia por maneiras alternativas, via os sentidos e o sensível, aquilo que me era apresentado de outras formas, por textos acadêmicos, entrevistas pensadas e algumas conversas provocadas. Essa forma de apreender o universo etnográfico já foi fonte de inspiração de textos de antropólogas como Favret-Saada (2005), ao discutir a potência da afetação do e da antropóloga ao longa da pesquisa. Dessa maneira, esses entendimentos se finalizavam na relação com o canto e dança do samba, mas estiveram embrenhados em percepções sobre os sons, os odores e as visualidades de onde passei.

\section{Os limites do acontecimento sensível}

Embora a dança e o canto pareçam ser as experiências ditadoras do ritmo das rodas, com o tempo passei a perceber que, na verdade, podemos entender os limites dos acontecimentos das 
rodas a partir de entendimentos relativos não só sobre os sons, mas também aos cheiros e as luzes. Esses mostravam os limites, o começo e o fim, fossem espaciais ou temporais, das rodas de samba femininas. Assim, falarei desses limites dentro dessas duas chaves: espaço e tempo. Essas chaves são importantes porque, a partir delas, é possível localizar-se dentro e fora das rodas: dentro e fora de acontecimentos simbólicos cujo pertencimento é desdobramento da vida social em sua forma mais "vital e concreta da experiência humana" (cavalcanti 2014), realizada e subjetivada a partir da experiência corporal.

\section{a audição}

O começo das rodas era marcado auditivamente por alguns pequenos ruídos. Ao observar minhas interlocutoras entendi que as rodas não iniciam quando as musicistas começavam a tocar o primeiro set. Ao contrário, começavam desde a organização de suas mesas e instrumentos. Assim, no começo, ouve-se pouco, em uma altura baixa, mas, de alguma maneira, sempre se está ouvindo algo. Normalmente, eram as organizadoras e as musicistas arranjando as mesas e seus instrumentos próximos à mesa. Fora elas, poucas pessoas estavam ali. Quando em um bar, havia também os funcionários e funcionárias, agitadas, tentando deixar tudo o mais preparado possível para quando o público chegasse, em massa, dali uma hora e meia.

Fora isso, havia o movimento das ruas, os carros, ônibus e transeuntes que ao passarem sempre deixavam algum rastro. Dali a pouco, esses sons mais externos e outros funcionais davam espaço à passagem de som. Nesse momento, as musicistas se permitiam testar seus instrumentos junto aos equipamentos de amplificação e os técnicos de som. Já ali o espaço se enchia de som. Essa passagem ainda não era capaz de abafar os outros sons, mas conseguia sobrepor-se a eles. Com o fim da passagem, o som das conversas voltava, já um pouco mais intensas, o estribilho dos passantes, fora os retoques finais de organização.

Quando já havia público suficiente, ou seja, quando já havia gente suficiente para formar um coro, as musicistas se ajeitavam e começavam a tocar o primeiro set. Até esse momento, eu costumava ficar próxima à organização delas, ou sozinha ou acompanhada por algum amigo ou amiga. Gostava de ficar próxima às musicistas no primeiro e no segundo set porque ao final de suas apresentações o público já estava muito tomado por uma energia calorosa e animada que, às vezes, me tocava bem, mas em outras oportunidades me impedia de permanecer ali, ainda prestando atenção aos movimentos. Por isso, eu tinha o costume de me afastar por alguns momentos e, depois, caso possível, voltava para algum ponto próximo às musicistas, já ao final das apresentações.

Nesses percursos, com a repetição, acabei me entendendo pelo que ouvia. Sabia que ainda estava muito próxima às musicistas quando as ouvia em determinada altura porque havia compreendido que ao me afastar verdadeiramente, primeiro, escutaria um mix entre as vozes das musicistas e do coro junto às vozes das pessoas que conversavam nos arredores. Um 
embaralhamento, fosse por um momento de necessária conversa com alguém, amigo, amiga, namorado, namorada ou para comprar cerveja com vendedores e vendedoras. Depois, ao me distanciar ainda mais, só ouvia conversas e o ruído das vozes que cantavam. Fora daquele limite, eu já não estava mais na roda. Em outros casos, quando chegava tarde, a partir daquele ponto, eu finalmente teria encontrado a roda.

Quando a roda chegava ao fim, ou seja, quando as musicistas terminavam seus sets, recolhiam seus instrumentos e abandonavam a mesa, havia um estremecimento. Isso porque, até a última música, estar próxima às musicistas e ao público, me fazia acreditar que eu só ouvia aqueles sons: as vozes e os instrumentos das musicistas, somados às vozes do público, que ecoavam. Com o final da última música, eu me chocava e me desconfortava com a perda dessas camadas, que pareciam tão certas e resistentes até ali. Esse desconforto certamente não era só meu, afinal, em quase todas as rodas denunciava-se a presença dos "inimigos do fim" dentre as musicistas e o público. Por diversas vezes, as musicistas se desculpavam bem-humoradamente: "pessoal, se não acabarmos agora, isso aqui vira uma rave". No melhor dos casos, o som de alguma DJ embalava a saída do local escolhido para aquelas rodas, mas, às vezes, restavam apenas as conversas, gargalhadas e passos que se multiplicavam ao redor.

\section{o olfato}

Se os sons formavam a camada talvez mais óbvia, os cheiros foram se tornando presentes e relevantes ao longo do tempo de pesquisa. No começo das rodas, era comum me deparar com o cheiro da limpeza do bar ou dos perfumes usados por alguém próximo a mim. Porque os começos também eram bastante esvaziados as experiências olfativas demoraram a surtir efeito em minha experiência etnográfica. A princípio, elas pareciam pano de fundo. Isso porque eu só as notava em situações limite: quando alguém derrubava cerveja próximo a mim ou em mim, ou quando eu comprava alguma bebida mais cheirosa que a cerveja, como uma caipirinha, ou quando ia ao banheiro e sentia cheiro de urina. Demorou até que eu notasse que ao chegar havia um certo frescor e ao sair ele havia se desgastado. Essa percepção surgia vagarosamente em meio aos comentários e conversas que desenvolvia com aqueles que me acompanhavam, as musicistas ou até mesmo desconhecidos - esses comumente me lembravam que ir ao banheiro ao fim de uma roda não era lá uma das melhores ideias. Desse modo, havia um enlace entre odor e tempo que apenas tardiamente se concretizou naquela experiência etnográfica, mesmo assim, sendo relevante auxiliar na concepção de uma participação ativa naqueles rituais.

Se no começo das rodas sentia os perfumes, tanto masculinos quanto femininos, bastante fortes e, às vezes, de marcas famosas, e o cheiro de limpeza dos bares, que não necessariamente limpavam tão bem seus aposentos, ao final, o cheiro de suor predominante era inegável. Da mesma forma, alguns hábitos das rodas, como o uso de bebidas, também se mostravam, principalmente pelo excesso. Alguns desses cheiros passaram a me localizar. Eu sabia que ainda 
estava na roda quando o cheiro de suor e de cerveja quente se faziam nítidos. O derrubar da cerveja era também algo característico: em meio à animação, canto e dança, os copos de cerveja caiam, esbarravam e se quebravam. Por outro lado, aos poucos fui me aproximando de uma experiência espacial de quem frequentava as rodas associada aquilo tido como "os arredores" dos eventos: esses se mostraram marcados pelo cheiro da urina nos asfaltos e calçadas de um verão bastante quente do Rio de Janeiro.

\section{a visão}

A visualidade já foi anteriormente discutida por seu papel constituidor de experiências rituais, principalmente as artísticas ou religiosas (Cavalcanti, 2002). A roda de samba embora seja associada principalmente à sonoridade e à ritmicidade, seja pela música ou pela dança, tem um apelo fortemente visual quando consideramos a importância da figuração espacial criada a fim de que os músicos e as musicistas assumam a centralidade. Fora isso, para além daquilo que se posiciona nos limites da mesa da roda, a visão faz parte de outro elemento importante para o seguimento desses festejos: que o público se veja. Essa possibilidade, de que as pessoas se entreolhem continuamente ao longo da festa, cria não somente uma sensação de participação e integralização à mesa, como desperta para a aproximação de desconhecidos pelo olhar. A visualidade em meio às rodas propicia inúmeros encontros, as vezes tomando, até mesmo, a forma do flerte. Assim, integrar-se à roda ou não, retribuir olhares ou não, fazem parte da experiência espacial e temporal daqueles ali presentes.

No que se refere especificamente às percepções de temporalidade em meio às rodas, foi se tornando evidente que as luzes serviam como relógio para quem ali estivesse. Quando as rodas começavam costumava ainda ser possível ver a luz do dia, principalmente porque à época da pesquisa ainda utilizávamos o horário de verão no Brasil. Logo, o começo das rodas costumava acontecer ainda sob a luz do sol, mesmo quando embaixo de algum toldo. Quando ele já começava a se pôr, as luzes dos bares e a que era instalada no próprio toldo eram acionadas de forma que a centralidade da iluminação fosse direcionada às musicistas. Os arredores iam se tornando cada vez mais escuros, contando apenas com a iluminação pública das ruas e, porventura, das varandas de algumas casas.

Quando a noite já estava consolidada e eu voltava a ver as musicistas e o público ao redor, invariavelmente eu pensava estar de frente com outras pessoas, ou pelo menos com lados mais maduros das mesmas pessoas. A iluminação alterava muito as percepções que tinha sobre aqueles corpos. Entretanto, a iluminação como recurso da visualidade não é uma novidade. Essa é uma técnica essencial para projetos fotográficos ou audiovisuais: nesses, a iluminação é um recurso central para a criação daquilo que se tem como o objeto da imagem. Ainda, com o tempo, passei a associar aquela compreensão visual do público e das musicistas com o fim da roda. Talvez o fato de que eu seja extremamente míope sobrecarregue esse elemento da minha 
experiência. De qualquer maneira, as luzes foram se tornando um ponto de observação cotidiana em meio às rodas porque elas eram capazes de tingir os acontecimentos, demarcando começo, meio e fim.

Outra forma de luz que constitui em grande medida a experiência visual das rodas era a dos flashs fotográficos, não apenas por sua aparição, mas principalmente por seu direcionamento. Naquele breve intervalo de tempo mobilizado para a organização das rodas, raramente vi disparos sendo direcionados às musicistas. Entretanto, com o início dos sets, invariavelmente, passavam a ocorrer disparos visando os grupos ou, até mesmo, uma musicista em particular. Disparos esses executados tanto pelo público quanto por fotógrafas contratadas pelas bandas ou pela organização das casas ou bares onde se apresentavam. Com o fim da roda e o começo da dispersão, esses flashs passavam a figurar o entorno, o público. Era comum ver grupos de amigos fazendo registros de suas participações ou encontros naqueles momentos do "pós-roda". Assim, os flashs também demonstravam, com seu efeito visual, a transformação dos espaços em meio aquele intervalo de tempo.

\section{O centro do acontecimento sensível}

Se na roda existiam sensações e percepções que mostravam os limites e demarcações daqueles acontecimentos, por outro lado, as experiências sensíveis de quem se conectava ao samba, fosse tocando na roda ou prestigiando as musicistas, se tornavam notáveis por meio das suas fontes de expressão: a dança e o canto. Elas foram importantes porque, além de comporem o envolvimento de todos e todas que participavam, elas também foram termômetros para que eu compreendesse, por exemplo, o que era o "empoderar-se" para as musicistas daquelas rodas.

Se o canto e a dança eram formas de conexão com o samba, também eram as formas mais básicas, mas principalmente visíveis, de conexão com os corpos de quem cantava e dançava. Ao acompanhar as performances das musicistas, notei que o empoderamento a que se propunham, o de ocupar as rodas de samba, acontecia quando seus corpos se conectavam com o menor número de impedimentos, medos e inseguranças em relação à música. Isso a princípio me tomou atenção pelas transformações de suas performances ao longo do intervalo de tempo de pesquisa (cerca de 7 meses). Notei que cada vez mais as mulheres que observava cantando e tocando instrumentos movimentavam-se com habilidade e segurança na roda: elas sorriam para o público, despreocupadas; convocavam com os braços e a fala quem pudesse acompanhá-las; e, com o tempo, foram tornando suas vozes mais límpidas, tornando mais fácil identificá-las por essas.

Assim, em meio às rodas, passei a entender que o empoderamento de que falavam se mostrava pela entrega aos acontecimentos de suas apresentações. Mais do que isso, o empoderamento falava sobre um aprendizado. Dominava as rodas quem as havia entendido, tanto pela ideia quanto pelo corpo. Daí a importância dada por elas aos ensaios, pois esses eram 
a plataforma utilizada pelas musicistas para que desenvolvessem seus conhecimentos e chegassem às rodas cada vez com maior domínio.

Por parte dos públicos, havia uma variedade de posturas frente ao canto e à dança. Era comum ver pessoas dançando de inúmeras formas e muitas simplesmente não sambavam. Era tão comum quanto ouvir os públicos cantando letras diferentes das que as musicistas cantavam. Da mesma maneira, uma parcela considerável dos públicos ia de encontro aos acontecimentos das rodas por meio de um conhecimento. Algumas pessoas sambavam, principalmente as mulheres, e outras cantavam os sambas, conheciam os "repertórios". De qualquer forma, apesar das diferenças, havia algo que conectava quem era parte dos públicos e quem performava. Um compartilhamento de experiência simbólica substantivado ao longo daqueles rituais.

A forma como as rodas eram construídas fazia com que, no primeiro set, as pessoas fossem se acomodando, entendendo aquele momento. Em seguida, no segundo set, empenhavase uma outra energia. As musicistas se enchiam de posturas mais vigorosas, cantavam mais alto e mobilizavam mais vezes os públicos, que a esse ponto já era consideravelmente grande e só aumentava. Entretanto, não eram apenas as musicistas mais vigorosas, o desenho dos repertórios das rodas também indicava sambas mais fortes e agitados para o segundo set, quando não só mais pessoas já estavam presentes, como mais pessoas já se encontravam alteradas pelo encontro com o samba e, muitas vezes, também com a cerveja. Isso tudo se concretizava ainda mais no terceiro set: a intensidade das pessoas, das músicas e das musicistas enfrentava o fim. Era necessário aproveitar ao máximo, pois aquele momento de entrega em breve acabaria. $\mathrm{O}$ entendimento do começo e do fim daqueles momentos era essencial para o envolvimento e entrega. Dessa maneira, é importante ressaltar o caráter da configuração dramática distribuída ao longo dos, normalmente, três sets de apresentação: a dramaticidade de cada um deles se dá de acordo com seu posicionamento entre o começo e o fim dos encontros, indo da apresentação das sambistas e de seu repertório base até o clímax, o terceiro set, quando costumam ser tocadas os sambas mais conhecidos, e envolventes, preparando a todos e todas para o fim.

As rodas, assim, foram se mostrando cada vez mais como um espaço sensível de aprendizado. Se as musicistas requeriam os ensaios para melhorarem suas performances - como elas me indicaram continuamente ao longo da pesquisa -, elas o faziam porque sentiam ao longo das apresentações anteriores, nas rodas, que havia elementos cuja qualidade ainda não as agradava. Era a atenção contínua aos acontecimentos das rodas que fazia com que elas se imbuíssem da responsabilidade de aprender algo que ainda não lhes parecia ideal. Embora não comprometidos profissionalmente, os públicos observavam e aprendiam com as musicistas. Entendiam não só pela observação, mas pela tentativa de incorporarem-se ao samba.

Tanto sambar quanto cantar são formas de expressão de um conhecimento que, na maioria das vezes, só pode ser expresso pelo próprio corpo. A dança pode ser vista como uma forma de conectar o corpo à música. Para realizar esses movimentos é necessário entender o que 
eles representam, pois há uma poética por trás dos esquemas corporais usados para sambar. Da mesma forma, ao cantar também se estabelece essa conexão entre corpo e música. Se a dança mobiliza o corpo de maneiras visíveis, o canto o mobiliza de formas audíveis. Tanto sambar quanto cantar um samba são movimentos com inúmeras cargas de dificuldade, pois há não só emoção, mas técnicas corporais. Como Mauss (2017) demonstra, essas técnicas demandam, muitas vezes, anos para se adequarem às vidas das e dos artistas. As técnicas corporais demandam longos processos de aprendizado, pois mover-se é uma questão de conhecimento. Da mesma maneira, ao se proporem a cantar, tocar, arranjar e dançar, as musicistas estavam se expondo às trajetórias de seus corpos, às técnicas que dominavam e a outras, que não dominavam ainda. Ao sentirem que algo lhes faltava, elas recorriam aos estudos e voltavam ao palco, dando novos significados a essas trajetórias. A construção das trajetórias se embasa no comportamento sensível, algo disponível a todos e todas e caro a todos e todas as artistas. Como Bateson (1972) analisa, os processos de aprendizado dos e das artistas são ininterruptos: ao finalmente compreender uma camada do fazer, o e a artista nota o que ainda não está em seu domínio, quando recomeça sua batalha pelo aprendizado.

Dessa maneira, compreender a poética disponível nos acontecimentos das rodas demandou um aprofundamento na dimensão sensível dos acontecimentos, por meio da atenção tanto aquilo que me era dito quanto aquilo que era silenciado, mas que poderia ser expresso de outras maneiras. A necessidade da sensibilidade residia aqui: era necessário que eu atentasse àquelas relações desenvolvidas e entrelaçadas em meio à pesquisa, ao longo de um período considerável. Muitas das explicações das interlocutoras, na verdade, não vieram em meio às nossas conversas e entrevistas, mas pelo desenrolar de suas atitudes, falas e posicionamentos ao longo do tempo. Muitos dos meus questionamentos eram respondidos por meio de respostas diretas às perguntas que eu elaborava ao deparar-me com uma nova situação. Outras, no entanto, se manifestavam pela mudança de repertório, no tocar de um novo instrumento, em uma nova forma de cantar: por meio de suas performances corporais.

\section{Conclusão}

Os processos de significação presentes em um ritual são o que possibilitam sua permanência ao longo do tempo. Rituais performático-artísticos, como as rodas de samba, mobilizam continuamente espaço e tempo ao evidenciar tais processos de significação, auxiliando a desenvolver as cargas simbólica e dramática dessas experiências sociais. Dessa maneira, os sentidos surgem como recurso analítico, que ao ser operacionalizado, aproxima-nos dos significados dados por quem participa desses rituais. Nas últimas páginas, o espaço centralizado das rodas de samba do Rio de Janeiro, bem como o fluxo de tempo flexibilizado dessas, foram mobilizadas a fim de desenvolver um olhar mais próximo às relações ali desenvolvidas. Ainda, buscou-se evidenciar a importância dos sentidos, como a visão, o olfato e 
a audição para a apreensão desses aspectos espaciais e temporais das rodas de samba cujas simbolizações foram centrais para a realização daquelas rodas de samba inteiramente femininas. A experiência dessas mulheres reforça a importância das experiências corporais, pois ao disputarem suas presenças nas rodas significam-nas por meio de suas trajetórias musicais e técnicas de corpo, o que chamaram de "empoderamento".

\section{Referências bibliográficas}

ADELMAN, Miriam. 2003. "Mulheres atletas: re-significações da corporalidade feminina". Revista Estudos Feministas, vol. 11, n.2: 445-465. DOI 10.1590/S0104-026X2003000200006

BATESON, Gregory. 1972 Steps to An Ecology of Mind. Chicago: University of Chicago Press.

BATLIWALA, Srilatha. 2007. "Taking the Power out of Empowerment - An Experiential Account”. In: Development in Practice, v.17, n 4-5, pp.557-565.

BERTH, Joice. 2018. O que é empoderamento? Belo Horizonte: Editora Letramento: Justificando. CAVALCANTI, Maria Laura. 2002. “Os sentidos no espetáculo”.: Revista de Antropologia, v.45, n.1: 37-78. DOI 10.1590/S0034-77012002000100002

CAVALCANTI, Maria Laura. 2013. "Drama, Ritual e Performance em Victor Turner". Sociologia \& Antropologia, vol. 03., n. 6: 411-440. DOI https://doi.org/10.1590/2238$38752013 \mathrm{v} 363$

CAVALCANTI, Maria Laura. 2014. "Introdução”. In.: CAVALCANTI, Maria Laura (Org.) Ritual e Performance: 4 estudos clássicos. Rio de Janeiro: 7Letras.

CEFAÏ, Daniel. 2010. "Provações corporais: uma etnografia fenomenológica entre moradores de rua de Paris”. Lua Nova, n.79: 71-110. DOI 10.1590/s0102-64452010000100005

CHAKRAVARTI, Uma. 2008. "Beyond the Mantra of Empowerment: Time to Return to Poverty, Violence and Struggle”. In: IDS Bulletin, n. 39: 10-17.

CLASSEN, Constance. 1993. Worlds of Sense: Exploring the senses in history and across cultures. Nova Iorque: Routledge.

CLASSEN, Constance. 2012. The Deepest Sense: A cultural history of touch. Chicago: University of Illinois Press.

COUTO, Caroline Peres. 2009. “'Samba das cabrochas': Identidades de gêneros e expressão emotiva em uma roda de samba no Rio de Janeiro (2008)”. In: Ponto Urbe, vol.5: s/p. DOI 10.4000/pontourbe.1545

CRISTIANO, Alexander da S. 2016. Trajetórias e Fronteiras no Mundo do Samba: João Martins e a nova geração de sambistas cariocas. Rio de Janeiro, Dissertação de Mestrado, Universidade Federal do Rio de Janeiro.

FRAVET-SAADA, Jeanne. 2005. "Ser afetado”. Tradução de Paula Siqueira. In: Cadernos de Campo, n.13: 155-161. DOI 10.11606/issn.2316-9133.v13i13p155-161 
GONÇALVES, Renata de Sá. 2008. A dança nobre no espetáculo popular: a tradição como aprendizado e experiência. Rio de Janeiro, Tese de Doutorado. Museu Nacional da Universidade Federal do Rio de Janeiro.

GRILLO, Bárbara. 2019. Um samba que elas querem: a voz das mulheres sambistas no Rio de Janeiro. Rio de Janeiro, Dissertação de Mestrado, Universidade Federal do Rio de Janeiro.

INGOLD, Tim. 2008. “Pare, Olhe, Escute! Visão, Audição e Movimento Humano”. Ponto Urbe, vol. 3: s/p. DOI 10.4000/pontourbe. 1925

JAQUET, Chantal. 2010. A Força do Corpo Humano. Tradução de Márcia Patrizio. São Paulo: Annablume.

JAQUET, Chantal. 2014. A Filosofia do Odor. São Paulo: Forense Universitária.

LE BRETON, David. 2016. Antropologia dos Sentidos. Petrópolis: Editora Vozes.

LOPES, Nei. 2008. Partido-alto: Samba de Bamba. Rio de Janeiro: Pallas.

MAGNANI, José Guilherme Cantor. 2005. “Os circuitos dos jovens urbanos”. In: Tempo social, São Paulo, v. 17, n. 2: 173-205. DOI 10.1590/S0103-20702005000200008

MAHMOOD, Sara. 2005. Politics of piety: the Islamic revival and the feminist subject. Princeton: Princeton University Press.

MAUSS, Marcel. 2017. “As técnicas do corpo”. In: Sociologia e Antropologia. São Paulo: Ubu Editora, pp. 421-446.

MERLEAU-PONTY, Maurice. 2018. Fenomenologia da Percepção. São Paulo: WMF Martins Fontes.

MIRANDA, Carmélia. 2019. "Mulheres quilombolas de Tijuaçu e o Samba de Lata: conquistas e empoderamento". In: SANTANNA, Marilda (Org.). As bambas do samba: mulher e poder na roda Salvador: EDUFBA.

MIZRAHI, Mylene. 2015. "Cabelos ambíguos beleza, poder de compra e 'raça' no Brasil urbano”. Revista Brasileira de Ciências Sociais vol. 30, n. 89: 31-45. DOI 10.17666/308931-45/2015

MOURA, Roberto M. 2004. No princípio, era a roda: um estudo sobre samba, partido alto e outros pagodes. Rio de Janeiro: Rocco.

PEIRANO, Mariza. 2006. “Temas ou teorias? O estatuto das noções de ritual e de performance”. Trabalho apresentado na mesa-redonda "Do Ritual à Performance". 25ª Reunião Brasileira de Antropologia. Goiânia, 2006.

PISCITELLI, Adriana. 2007. "Corporalidade em confronto: brasileiras na indústria do sexo na Espanha”. Revista Brasileira de Ciências Sociais, vol. 22, n. 64: 17-32. DOI 10.1590/S010269092007000200002

SANDRONI, Carlos. 2012. Feitiço decente: Transformações do samba no Rio de Janeiro (19171933). Rio de Janeiro: Zahar. 
SARDENBERG, Cecília. M. B. Conceituando "empoderamento" na perspectiva feminista. I Seminário Internacional: Trilhas do Empoderamento de Mulheres - Projeto TEMPO', NEIM/UFBA, Salvador, Bahia, de 5-10 de junho de 2006.

SODRÉ, Muniz. 1998. Samba, o dono do corpo. Rio de Janeiro: Mauad.

SOLIS, Victor N. F. 2017. Apoteose ao Samba: Sambas, Sambistas e suas estratégias de afirmação de identidade, memória e resistência nos espaços sociais (anos 1930 a 1960). Rio de Janeiro, Tese de Doutorado, Universidade do Estadual do Rio de Janeiro.

TROTTA, Felipe. 2011. O samba e suas fronteiras: o pagode romântico e samba de raiz nos anos 1990. Rio de Janeiro: EdUFRJ.

TURNER, Victor. 1974. O processo ritual: estrutura e anti-estrutura. Petrópolis: Vozes.

URRY, John. 2000. Sociology Beyond Societies. Mobilities for the Twenty First Century. London: Routledge.

VIANNA, Hermano. 1995. O mistério do samba. Rio de Janeiro: Zahar.

sobre a autora

\section{Barbara Grillo}

Mestra em Antropologia e Sociologia pela Universidade Federal do Rio de Janeiro.

Contribuição de Autoria: Não se Aplica

Financiamento: CAPES

Recebido em 26/01/2021

Aceito para publicação em 22/10/2021 
